\title{
Desempenho de Novilhos Consumindo Suplemento Mineral Proteinado Convencional ou com Uréia
}

\author{
Marcus Antonio Zanetti ${ }^{1}$, José Mauro Luiz Resende ${ }^{2}$, Fernando Schalch ${ }^{3}$, Cláudia Maria Miotto ${ }^{2}$
}

RESUMO - Foram utilizados 48 bovinos mestiços, com a finalidade de testar quatro suplementos minerais comerciais: Tratamento A - Sal proteinado sem uréia (com 20\% de proteína bruta); B - Sal proteinado com uréia (com 52,5\% de proteína bruta); C - Sal mineral; e D - Sal mineral com uréia (91\% de proteína bruta). Os 48 animais foram distribuídos em 24 piquetes de capim Braquiaria decumbens, com suplementação de 10,5 kg de cana-de-açúcar/cab./dia, durante 112 dias, sendo 28 de adaptação e 84 de coleta de dados. Os animais foram pesados no início e no final do experimento, sendo que o controle da ingestão do suplemento mineral foi realizado semanalmente. O ganho de peso e o consumo do suplemento, em g/dia, nos tratamentos A, B, C e D, foram: 86 e 325; 357 e 650; -96 e 57; e 207 e 135, respectivamente. O pior resultado foi obtido pelos animais que receberam apenas sal mineral e o melhor, pelos animais que receberam o suplemento proteinado com uréia. O grupo que recebeu proteinado sem uréia apresentou desempenho semelhante ao do grupo que recebeu apenas sal mineral com uréia.

Palavras-chave: bovinos, mineral, sal proteinado, suplemento, uréia

\section{Performance of Steers Fed Different Protein Supplements in the Mineral Mixtures}

\begin{abstract}
Forty-eight crossbreed beef cattle were used to evaluate four commercial mineral supplements: Treatment ASalt + protein without urea (20\% crude protein); B - salt + protein with urea (52,5\% crude protein), C) mineralized salt; D) mineralized salt with urea (91\% crude protein). The animals were distributed into 24 plots of Braquiaria decubens grass, with supplementation of ( $10.5 \mathrm{~kg} / \mathrm{an} / \mathrm{day})$ of sugar cane, during 112 days, with 28 days of adaptation and 84 days of data collection. The animals were weighed at the beginning and at the end of the experiment, and the mineral supplement intake was weekly controlled. The weight gain and the mineral supplement intake (g/d) for the treatments A, B, C and D were 86 and 325, 357 and 650, -96 and 56, 207 and 135, respectively. The worst result was observed for the animals that received only mineralized salt and the best was obtaneid by the animals that received salt with protein with urea. The animals that received salt with protein without urea showed similar performance to the group that received only mineralized salt with urea.
\end{abstract}

Key Words: mineral supplementation, mineral mixture, steers, urea

\section{Introdução}

No Brasil, existe estacionalidade na produção de forragens, com grande produção no período das águas (cerca de $80 \%$ ) e deficiência no período das secas (PEDREIRA, 1973), refletindo de maneira significativa na produção animal, tornando-se necessária a suplementação para os animais a pasto.

BISSCHOFF et al. (1967) realizaram vários experimentos de suplementação em pastagens, utilizando basicamente dois concentrados protéicos, com um nível de proteína considerado alto (43\%) e outro baixo (24\%), sendo que ambos possuíam uréia em suas fórmulas. No experimento dois, o lote testemunha, que recebeu apenas pastagem de colonião de boa qualidade, ganhou por dia $0,184 \mathrm{~kg}$, enquanto os suplementados com 0,5 e $1 \mathrm{~kg}$ do concentrado alta proteína ganharam, respectivamente, 0,173 e $0,250 \mathrm{~kg}$, e os suplementados com o concentrado de baixa proteína, 0,131 e $0,137 \mathrm{~kg} / \mathrm{dia}$. No experimento três, foram utilizadas pastagens de jaraguá e de grama batatais, consideradas de média qualidade; neste caso, os animais mestiços zebu do lote testemunha perderam por dia $0,095 \mathrm{~kg}$, enquanto os suplementados com 0,5 e $1 \mathrm{~kg}$ do concentrado contendo $24 \%$ de proteína perderam 0,026 e $0,044 \mathrm{~kg}$, respectivamente, e os suplementados com 0,5 e $1,0 \mathrm{~kg}$ do concentrado contendo $43 \%$ de proteína ganharam 0,054 e 0,207 kg/dia.

VILELA et al. (1981) estudaram o efeito da adição de uréia à mistura mineral sobre o ganho em

\footnotetext{
1 Professor Titular da Faculdade de Zootecnia e Eng. de Alimentos da USP em Pirassununga.

2 Zootecnista.

${ }^{3}$ Médico Veterinário do Campus da USP em Pirassununga.
} 
peso de bezerros desmamados, em pastejo, durante o período de seca. Foram utilizados 90 bezerros desmamados, em pastagem de Braquiaria decumbens, distribuídos em três tratamentos que consistiram em mistura mineral com 0,25 e $50 \%$ de uréia. Após 120 dias de suplementação, constatou-se efeito positivo da uréia, com ganhos médios de 0,$280 ; 0,370 ;$ e 0,460 $\mathrm{kg} / \mathrm{an} . / \mathrm{dia}(\mathrm{P}<0,05)$. Os consumos de uréia foram de 0,16 e 30 g; cloreto de sódio, 30, 25 e 20 g; e mistura mineral, de 35,49 e $30 \mathrm{~g}$, para os tratamentos A, B e $\mathrm{C}$, respectivamente.

No experimento de HAFLEY et al. (1989), foram estudados os efeitos da suplementação de diferentes tipos de proteína para novilhos em pastagem de verão. Apesar de a pastagem apresentar teores de proteína bruta variando entre 8 e $14 \%$, os autores encontraram baixos níveis de amonia ruminal $(<6 \mathrm{mg}$ $\mathrm{NH}_{3} / 100 \mathrm{~mL}$ ). Os tratamentos consistiram de: A) controle negativo; B) controle energético; C) $0,137 \mathrm{~kg} / \mathrm{animal} / \mathrm{dia}$ de proteína não-degradável; D) $0,182 \mathrm{~kg} /$ animal $/$ dia de proteína degradável; e E) $0,364 \mathrm{~kg} / \mathrm{animal} / \mathrm{dia}$ de uma mistura de proteína degradável e não-degradável. O melhor resultado foi obtido pela mistura das duas proteínas, que propiciaram ganhos em peso superiores ao controle $(0,73$ versus 0,62 e $0,62 \mathrm{~kg} / \mathrm{an} . / \mathrm{dia})$. Os grupos de animais que receberam proteína não-degradável e degradável ganharam 0,65 e 0,67 kg/an/dia, respectivamente. Os autores concluíram que houve tendência de maiores ganhos com proteína degradável, sendo que este fato, aliado aos baixos níveis de amônia ruminal, indicou que a degradação da proteína de gramíneas de clima quente é baixa. $\mathrm{O}$ aumento no ganho de peso com a mistura dos dois tipos de proteína sugere que a proteína não-degradável da gramínea não é bem utilizada pelo animal, uma vez que houve resposta positiva para a proteína não-degradável adicional, mostrando que esta foi utilizada no trato digestivo baixo, ao contrário da fração correspondente da gramínea, que não deve ter sido aproveitada, como seria de se esperar.

McCOLLUM III e HORN (1989) afirmaram que os suplementos protéicos geralmente aumentam o desempenho animal em pastagens, devido a vários fatores, sendo o aumento na ingestão de forragem o principal. No caso de pastagem com menos de $7 \%$ de proteína, o nitrogênio suplementar fornecido aos microrganismos aumenta a síntese protéica e a taxa de digestão; também é importante a proteína que passa pelo rúmen, sem ser degradada. O maior fluxo de proteína melhora a eficiência da utilização da ener- gia, em nível de tecido, pelo fornecimento de aminoacidos deficientes, provendo substratos glicogênicos e também melhorando o $\mathrm{N}$ ruminal por intermédio da reciclagem do nitrogênio. Segundo os autores, um dos grandes problemas é determinar quando suplementar e qual é o melhor tipo de proteína (degradável ou não-degradável), uma vez que os resultados variam com os experimentos e os diferentes locais. A aplicação de programas de suplemantação é limitada pela falta de conhecimento do modo de ação dos suplementos em relação às características das pastagens e do animal. No experimento realizado por BARGO e REARTE (1998), em que foram utilizados suplementos com dois níveis de proteína de alta e baixa degradabilidade, para vacas em pastagem de aveia forrageira, não houve diferença na ingestão de matéria seca (MS) e no pH ruminal, sendo que, no grupo suplementado com baixa proteína e no de baixa degradabilidade (farinha de penas), houve menor nível de amônia ruminal.

OROPEZA et al. (1998) obtiveram ganhos de $540 \mathrm{~g} / \mathrm{d}$ para bovinos em pastagem tropical, suplementados com $2 \mathrm{~kg}$ de concentrado mais mistura mineral. Foi verificado que os animais suplementados ingeriram a mesma quantidade de matéria seca que os animais que receberam apenas pasto.

Um dos inconvenientes da suplementação com mistura mineral contendo proteína e/ou energia é a grande variação no consumo, que depende, além de outros fatores, da qualidade e da oferta da pastagem. (LOPES et al., 1997). A variação no consumo é também observada quando é oferecida apenas a mistura mineral, sendo que a ingestão geralmente não está relacionada com as exigências minerais (McDOWELL, 1996).

O objetivo deste presente experimento foi testar quatro suplementos minerais existentes no mercado, na época de seca, para animais em pastagem de braquiária, recebendo suplementação de cana-deaçúcar.

\section{Material e Métodos}

O presente experimento foi realizado na Faculdade de Zootecnia e Engenharia de Alimentos da Universidade de São Paulo, no Campus de Pirassununga, no período de seca, com o objetivo de avaliar quatro suplementos minerais comerciais contendo proteína verdadeira e nitrogênio não-protéico. Foram utilizados 48 bovinos mestiços Nelore x Caracu, 24 machos 
castrados e 24 fêmeas, com peso vivo inicial médio de $207,3 \mathrm{~kg}$, distribuídos em quatro tratamentos, a saber: Tratamento A - sal proteinado sem uréia; B - sal proteinado com uréia; $\mathrm{C}$ - sal mineral e D - sal mineral com uréia. Os 48 animais foram distribuídos em 24 piquetes de capim Braquiária decumbens, sendo um macho e uma fêmea por piquete de 0,1 ha. Os animais receberam suplementação de $10,5 \mathrm{~kg}$ de cana-deaçúcar/cab./dia. Cada piquete possuía bebedouro, cocho para forragem e cocho para sal mineral. O experimento teve duração de 112 dias, sendo 28 dias de adaptação e 84 de coleta de dados.

Os animais foram pesados a cada 28 dias e o consumo das misturas foi controlado semanalmente. Os piquetes foram amostrados no início e final do experimento.

Na Tabela 1, são apresentados os níveis de garantia das misturas utilizadas.

No início do experimento, havia disponibilidade média de forragem, nos piquetes, de $442 \mathrm{~kg}$ MS e no final, de $357 \mathrm{~kg}$ MS. Os pastos apresentaram, em média, na matéria seca $5,5 \%$ de proteína bruta $(\mathrm{PB})$, $33 \%$ de fibra bruta (FB), 0,4 Ca e 0,1 P, enquanto a cana-de-açúcar apresentou, em média, na matéria seca $3,2 \% \mathrm{~PB}, 25,6 \% \mathrm{FB}, 0,25 \%$ de $\mathrm{Ca}$ e $0,04 \% \mathrm{P}$.

\section{Resultados e Discussão}

A parte volumosa da ração caracterizou-se por ser deficiente em proteína, uma vez que o pasto apresentou, em média, 5,5\% de proteína e a cana-deaçúcar, 3,2\%, sendo que devido à época de seca, ambas as proteínas devem ser consideradas de baixa qualidade. A parte energética foi menos crítica, devido à presença de cana-de-açúcar.

Na Tabela 2, são apresentados os ganhos de peso médios durante o período experimental, bem como o consumo das misturas minerais.

Como pode ser verificado, o pior desempenho foi apresentado pelos animais que receberam apenas a mistura mineral (perda diária de $96 \mathrm{~g}$ ). Os animais que receberam proteinado sem uréia ganharam $86 \mathrm{~g} / \mathrm{d}$ e estatisticamente não diferiram dos animais suplementados com uréia que ganharam $207 \mathrm{~g} / \mathrm{d}$. A explicação para este fato é a maior ingestão de nitrogênio por este último grupo, que era o nutriente limitante não só devido ao baixo teor do pasto (que era muito limitado), mas principalmente pelo fornecimento da cana-de-açúcar, que é muito pobre em proteína. O proteinado propiciou ingestão de $64 \mathrm{~g} \mathrm{~PB}$, enquanto o sal com uréia, $123 \mathrm{~g}$. O melhor desempenho no presente experimento (ganho de $357 \mathrm{~g} / \mathrm{dia}$ ) foi apresentado pelo grupo que recebeu o proteinado com uréia, que também apresentou o maior consumo tanto de suplemento (650 g/dia), quanto de PB (341 g), indicando que no presente experimento foi importante o nível de nitrogênio, e não a degradabilidade da proteína. Estes resultados foram semelhantes aos obtidos por HAFLEY et al. (1989), que obtiveram o melhor resultado para o suplemento que continha mistura de proteína degradável e não-degradável, e também semelhantes aos obtidos por VILLELA et al. (1981), que obtiveram resultados positivos com a suplementação de uréia para animais em pasto de braquiária. No experimento realizado por OROPEZA et al. (1998), os animais ganharam $540 \mathrm{~g} /$ dia, porém

Tabela 1 - Níveis de garantia das misturas utilizadas nos diversos tratamentos (macroelementos em \% e microelementos em $\mathrm{mg} / \mathrm{kg}$ )

Table 1 - Tag levels of mineral mixtures used in the different treatments (macroelements in \% and microelements in ppm)

\begin{tabular}{lcccc}
\hline $\begin{array}{c}\text { Nutrient } \\
\text { Nutrient }\end{array}$ & $\begin{array}{c}\text { Proteinado } \\
\text { Protein }\end{array}$ & $\begin{array}{c}\text { Proteinado + uréia } \\
\text { Protein }+ \text { urea }\end{array}$ & $\begin{array}{c}\text { Sal mineral } \\
\text { Mineral salt }\end{array}$ & $\begin{array}{c}\text { Sal mineral + uréia } \\
\text { Mineral salt }+ \text { urea }\end{array}$ \\
\hline $\mathrm{PB}$ & 20,00 & 52,50 & 0,00 & 91,00 \\
$\mathrm{CP}$ & & & & \\
$\mathrm{Ca}$ & 1,70 & 1,30 & 8,74 & 7,28 \\
$\mathrm{P}$ & 0,93 & 1,15 & 6,84 & 5,37 \\
$\mathrm{Na}$ & 11,72 & 4,69 & 20,35 & 14,39 \\
$\mathrm{Mg}$ & 0,55 & 0,08 & 0,62 & 0,63 \\
$\mathrm{~S}$ & 0,87 & 0,57 & 1,25 & 1,25 \\
$\mathrm{Cu}$ & 275,00 & 250,00 & 2100,00 & 2100,00 \\
$\mathrm{Zn}$ & 1026,00 & 1080,00 & 3650,00 & 3600,00 \\
$\mathrm{I}$ & 20,00 & 24,00 & 135,00 & 135,00 \\
$\mathrm{Se}$ & 7,00 & 5,00 & 23,00 & 23,00 \\
$\mathrm{Co}$ & 36,00 & 45,00 & 119,00 & 119,00 \\
\hline
\end{tabular}


Tabela 2 - Ganho de peso e consumo dos suplementos, média diária em gramas

Table 2 - Weight gain and supplement intake, daily average in grams

\begin{tabular}{|c|c|c|c|c|}
\hline \multirow{3}{*}{$\begin{array}{l}\text { Tratamento } \\
\text { Treatment }\end{array}$} & \multicolumn{2}{|c|}{$\begin{array}{l}\text { Ganho de } \\
\text { peso } \\
\text { Weight gain }\end{array}$} & \multicolumn{2}{|c|}{$\begin{array}{c}\text { Consumo } \\
\text { suplemento } \\
\text { Supplement intake }\end{array}$} \\
\hline & Média & $\mathrm{CV}$ & Média & $\mathrm{CV}$ \\
\hline & Mean & & Mean & \\
\hline $\begin{array}{l}\text { Proteinado } \\
\text { Protein }\end{array}$ & $86^{\mathrm{b}^{*}}$ & 129 & $320^{\mathrm{b}}$ & 48 \\
\hline $\begin{array}{l}\text { Proteinado + uréia } \\
\text { Protein }+ \text { urea }\end{array}$ & $357^{a}$ & 29 & $650^{\mathrm{a}}$ & 22 \\
\hline $\begin{array}{l}\text { Sal mineral } \\
\text { Mineral mixture }\end{array}$ & $-96^{c}$ & 142 & $56^{\mathrm{c}}$ & 17 \\
\hline $\begin{array}{l}\text { Sal mineral + uréia } \\
\text { Min. mixture + urea }\end{array}$ & $207^{b}$ & 43 & $135^{\mathrm{c}}$ & 26 \\
\hline
\end{tabular}

consumiram somente $2 \mathrm{~kg}$ de suplemento/dia.

Quanto ao tipo de proteína, é interessante frisar que, no estudo realizado por BARGO e REARTE (1998), a suplementação com proteínas de alta e baixa degradabilidade não teve efeito na ingestão de matéria seca, não sendo medido o ganho de peso, devido ao baixo número de animais e ao curto período experimental. No trabalho realizado por BROWN e PATE (1997), os bovinos alimentados com feno amoniado apresentaram desempenho superior, quando receberam suplementos farelo de algodão ou farinha de penas em comparação com uréia (média e baixa degradabilidade em comparação com alta degradabilidade). FRANCO (1997) não notou diferença na degradação ruminal da MS, PB e FDN da forragem, quando se realizou suplementação com proteína de baixa, média e alta degradabilidade, nos níveis de 0,$5 ; 1,0 ;$ e $1,5 \mathrm{~kg} / \mathrm{cab} . /$ dia.

Considerando as exigências do NATIONAL RESEARCH COUNCIL - NRC (1996), para animais de $200 \mathrm{~kg}$ de peso vivo, com ganho de $0,5 \mathrm{~kg}$ e ingestão de 4,0 $\mathrm{kg} \mathrm{MS} / \mathrm{dia}$, as ingestões dos suplementos minerais e seus respectivos níveis de garantia, foi elaborada a Tabela 3, na qual são apresentadas as porcentagens das ingestões dos elementos minerais via suplementos, com relação às exigências. Os dados mostram valores elevados, principalmente para os minerais proteinados, devendo constituir-se em motivo de preocupação, uma vez que o consumo deste tipo de alimento é considerado muito variável. O sal comum $(\mathrm{NaCl})$ é um elemento considerado de grande importância para limitar o consumo do suplemento e, segundo RICH e GILL (1998), animais com $210 \mathrm{~kg}$ de peso vivo devem consumir diariamente $250 \mathrm{~g}$ de sal comum para que o consumo do suplemento seja controlado. No presente experimento, a ingestão de $\mathrm{NaCl}$ pelos animais suplementados com proteinado e proteinado mais uréia foi de 101 e 86 g, respectivamente, valores estes bem inferiores aos citados pelos autores, mostrando que o sal comum é apenas uma da variáveis. É sabido que alguns alimentos como, por exemplo, o farelo de algodão é altamente palatável e pode alterar o consumo de maneira significativa. No trabalho desenvolvido pela Embrapa (LOPES et al., 1997), os autores afirmaram que o consumo é bastante variável e, com mistura contendo $30 \%$ de $\mathrm{NaCl}$, o consumo do proteinado deve-se situar entre 200 e $300 \mathrm{~g} /$ dia.

Tabela 3 - Minerais ingeridos (\%) em relação às exigências

Table 3 - Minerals intake (\%) in relation to the requirements

\begin{tabular}{lcccc}
\hline Elemento & \multicolumn{4}{c}{$\begin{array}{c}\text { Suplemento } \\
\text { Supplement }\end{array}$} \\
\cline { 2 - 5 } & Proteinado & $\begin{array}{c}\text { Proteinado + uréia } \\
\text { Protein }+ \text { urea }\end{array}$ & $\begin{array}{c}\text { Sal mineral } \\
\text { Mineral salt }\end{array}$ & $\begin{array}{c}\text { Sal mineral + uréia } \\
\text { Mineral salt }+ \text { urea }\end{array}$ \\
\hline & Protein & 42,50 & 24,50 & 49,00 \\
$\mathrm{Ca}$ & 27,00 & 68,18 & 65,45 \\
$\mathrm{P}$ & 27,27 & 1089,28 & 34,54 & 692,86 \\
$\mathrm{Na}$ & 1339,28 & 12,50 & 407,14 & 20,00 \\
$\mathrm{Mg}$ & 45,00 & 61,67 & 7,50 & 28,33 \\
$\mathrm{~S}$ & 100,00 & 7300,00 & 11,67 & 4025,00 \\
$\mathrm{Co}$ & 2875,00 & 406,25 & 1675,00 & 708,75 \\
$\mathrm{Cu}$ & 220,00 & 780,00 & 294,00 & 910,00 \\
$\mathrm{I}$ & 320,00 & 800,00 & 380,00 & 775,00 \\
$\mathrm{Se}$ & 550,00 & 585,00 & 325,00 & 405,00 \\
$\mathrm{Zn}$ & 273,58 & & 170,00 & \\
\hline
\end{tabular}




\section{Conclusões}

A mistura mineral com $52 \%$ de proteína bruta propiciou ganho de peso superior aos demais suplementos.

\section{Referências Bibliográficas}

BENINTENDI, R.P., FREITAS, E.A.N., BIONDI, P. 1974. Efeito da administração de suplemento de milho desintegrado, durante a seca, a novilhas das raças gir e sindi. Bol. Ind. Anim., 31(2): 221-7.

BISSCHOFF, W.V.A., QUINN, L.R., MOTT, G.O. et al. 1967. Suplementações alimentares protéico-energéticas de novilhos em pastejo. Pesq. Apropec. Bras., 2:421-436.

BROWN, W.F., PATE, F.M. 1997. Cottonsees meal or feather meal supplementation of ammoniated tropical grass hay for yearling cattle. J. Anim. Sci., 75:1666-1673.

FRANCO, A.V.M., Avaliação dos parâmetros ruminais em bovinos suplementados a pasto na estação seca. Jaboticabal, SP: UNESP, 1997. 56p. Tese (Doutorado em Zootecnia) Universidade Estadual Paulista, 1997.

HAFLEY, J., ANDERSON,B.E., KLOPFENSTEIN,T.J. 1989. Rumen protein degradation of warm-season grass. J. Anim. Sci., 67(suppl.1): 305.

LOPES, H.O.L., PEREIRA, E.A., SOARES, W.V. et al. 1997. Mistura múltipla - uma alternativa de baixo custo para suplementação alimentar do gado na época da seca. 2.ed. EMBRAPA. 5p (Comunicado Técnico, 68).

McCOlluM III, F.T., HORN, G.W. 1989. Protein supplementation of grazing ruminants. J. Anim. Sci., 67:304(suppl. 1).
McDOWELL, L.R. 1996. Feeding minerals to cattle on pasture. Anim. Feed. Sci. Tech., 60:247-271.

MATTOS, J.C.A., TUNDISI, A.G.A., VELlOSO, L. et al. 1967. Contribuição para o estudo da alimentação de bovinos durante o período de seca. Bol. Ind. Anim., 24:17-23.

NATIONAL RESEARCH COUNCIL - NRC. 1996. Nutrients requirements of beef cattle. 7.ed. Washington, D.C. 242p.

OROPEZA, O.G., GONZALEZ, S.S., GARCIA-BOJALIL C. et al. 1998. Effect os a supplement, mineral salt and ionophore on intake, digestibility and weight gain os growing bullocks grazing tropical pastures. J. Anim. Sci., 76:292(suppl. 1).

PEDREIRA, J.V.S. 1973. Crescimento estacional dos capins Panicum maximum Jacq, Melinis minutiflora Pal de Beauv, Hiparrhenia rufa (Ness) Stapf e Digitaria pentz II Stent. Bol. Ind. Anim., 30(1):59-145.

RICH, T.D., GILL, D.R. Limiting feed intake with salt, G76-324A. agcm042@unlvm.edu (22 out 1998)

VILELA, H., DEMTCHENKO, A., VILELA, D. et al. Efeito da adição de uréia à mistura mineral sobre o ganho em peso de bezerros desmamados, em pastejo, durante o período de seca. In: REUNIÃO ANUAL DA SOCIEDADE BRASILEIRA DEZOOTECNIA, 18, Goiânia, 1981. Anais... Goiânia: SBZ, 1981, p.353.

Recebido em: 30/04/99

Aceito em: 11/10/99 


\section{ERRATA}

Rev. bras. zootec., 29(2):452-457, 2000

\section{Onde se lê:}

Influência do Período de Serviço no Início da Lactação sobre a Relação entre a Produção de Leite e o Período de Serviço de Vacas da Raça Holandesa

\section{Leia-se:}

Influência da Produção no Início da Lactação na Relação entre a Produção de Leite e o Período de Serviço de Vacas da Raça Holandesa

\section{Onde se lê:}

Effect of Days Open During Early Lactation on the Relations Between Milk Production and Days Open in Holstein Cows

\section{Leia-se:}

Effect of Yield During Early Lactation on the Relationship Between Milk Production and Days Open in Holstein Cows 